\title{
A ESCOLA E A CONSTRUÇAO DAS ESTRUTURAS DA INTELIGÊNCIA NA CRIANÇA
}

\section{Orly Zucatto Mantovani de Assis}

\begin{abstract}
Resumo
Neste artigo, apresentamos resultados de pesquisas realizadas com crianças de 7 à 9 anos, apoiandonos nos pressupostos da teoria piagetiana - que fundamenta a compreensão das relações entre ensino, aprendizagem e desenvolvimento - objetiva verificar se a escola proporciona, verdadeiramente, aos seus alunos, a oportunidade de desenvolverem plenamente sua personalidade, a construção da inteligência, da moralidade, contribuindo para a formação de um cidadão apto a cooperar, ser solidário e capaz de empreender transformações sócio-culturais.
\end{abstract}

\section{Palavras-chave}

Ensino-aprendizagem ; Desenvolvimento ; Moralidade ; Construtivismo

In this article, we presented results of researches accomplished with children of 7 to 9 years, leaning on in the presuppositions of the theory piagetiana - that bases the understanding of the relationships among teaching, learning and development - it objectifies to verify the school it provides, truly, to its students, the opportunity of they develop its personality fully, the construction of the intelligence, of the morality, contributing to the a capable citizen's formation to cooperate, to be solidary and capable of undertaking partner-cultural transformations.

\section{Key-words}

Teaching-Learning ; Development ; Morality ; Constructivism 
Nas poucas obras que PIAGET dedicou à educação, o autor ressalta inúmeras vezes a importância do papel da escola na formação de pessoas intelectual e moralmente autônomas. Para isso é preciso que essa instituição assuma não apenas a responsabilidade de ensinar a ler, escrever e contar. Sua função é muito mais importante do que essa. A escola deve proporcionar ao aluno a oportunidade de desenvolver plenamente sua personalidade no que se refere à construção da inteligência, da moralidade e contribuir de maneira decisiva para a formação de um cidadão apto a cooperar, a ser solidário e capaz de empreender transformações sociais e culturais. Mas estará a escola conseguindo executar bem suas funções? Estará o aluno tendo oportunidade de encontrar na escola um ambiente educacional que lhe possibilite construir, até a conclusão, os instrumentos indispensáveis de adaptação ao meio físico e social que são as operações da lógica, como afirma PIAGET (1973, p.38), numa de suas obras sobre educação?

Neste trabalho procuraremos responder a essas questões, recorrendo aos resultados de nossas pesquisas (Mantovani de Assis, 1976, 1982) que tiveram origem na experiência que vivemos como professora de primeira série do ensino fundamental durante quase quinze anos.

Em geral, a maioria dos alunos apresentava muita dificuldade em aprender as noções de matemática elementar. Ao final do ano escolar, após repetirem inúmeros exercícios gráficos, tais dificuldades eram aparentemente superadas e os alunos promovidos.

Entretanto, quando iniciavam a $2^{\mathrm{a}}$ série, após as férias de verão, demonstravam ter esquecido a maior parte do conteúdo de matemática que haviam aprendido no ano anterior. A repetição desses fatos ano após ano e a necessidade de explicá-los determinou nossa decisão de fazer o curso de pedagogia e, posteriormente, as disciplinas do programa de pós-graduação a nível de mestrado, culminando com o doutorado em 1976. Em nossa tese de doutorado (Mantovani de Assis, 1976), tentamos explicar por que depois de terem aprendido as operações da matemática elementar, os alunos esqueciam quase tudo, a tal ponto que na segunda série era necessário recomeçar o programa dessa disciplina.

A leitura de alguns livros da obra de Jean Piaget e seus seguidores, os cursos da Prof.a Dra. Zélia Ramozzi-Chiarottino, foram fundamentais para que pudéssemos compreender as relações entre ensino, aprendizagem e desenvolvimento e, conseqüientemente, entender o que acontecia com nossos alunos, à luz da teoria piagetiana.

PIAGET explica que, para compreender ou conhecer, é preciso que o dado exterior seja assimilado às estruturas intelectuais do sujeito, o que só é possível se tais estruturas existirem anteriormente. Por conseguinte, para aprender as noções matemáticas mais simples, como, por exemplo, a noção de número e as operações de adição, subtração, multiplicação e divisão, o sujeito precisa ter à sua disposição estruturas mentais que lhe possibilitem adquirir as noções matemáticas e as operações numéricas. Isso ocorre porque uma aprendizagem não parte jamais do zero (PIAGET, 1959), pois o novo elemento é reorganizado internamente a partir das aquisições anteriores. Dessa reorganização surgem novas combinações que abrem possibilidades para a aprendizagem de novos dados com os 
quais o sujeito se defronta na medida em que interage com o meio.

Tomando por base esses aspectos da teoria piagetiana, pode-se afirmar que as informações que a criança recebe na escola somente poderão ser compreendidas se existirem, previamente, em seu intelecto, estruturas que possam assimilá-las, reorganizá-las. Essas estruturas são as de natureza lógicomatemática ou estruturas operatórias sem as quais a criança não poderia compreender nada do que lhe ensina a escola (PIAGET, 1979, p.55).

Nessas afirmações de PIAGET encontramos uma explicação possível para o problema que nos inquietava: se com 7 anos de idade, ao ingressar na escola de ensino fundamental, a criança não possuísse as estruturas lógicas elementares, não teria condições de assimilar os conteúdos de matemática. Assim sendo, seu desempenho nessa disciplina que garante a aprovação de uma série para outra, somente poderia ser explicado pela memorização. Ora, tudo o que é apenas memorizado é passível de ser esquecido. A ausência de estruturas mentais adequadas no pensamento da criança poderia ser a causa do fracasso que a grande maioria de alunos experimenta em relação à matemática em qualquer grau de ensino.

Todavia, para que esta explicação pudesse ser aceita era preciso comprovála. Porém, aqueles que foram nossos alunos não poderiam ser estudados, pois continuaram sua trajetória pela escola de ensino fundamental e deveriam estar naquela época na $4^{\mathrm{a}}$ ou $5^{\mathrm{a}}$ série e com mais de 10 anos idade.

Como todos sabem, em nosso país a lei estabelece um limite cronológico, a partir do qual a entrada da criança na escola é obrigatória. Se com essa idade a criança não houver construído as estruturas lógicas elementares, a compreensão de conteúdos escolares que implicam raciocínio lógico ficará comprometida.

Com o objetivo de verificar a natureza das estruturas de pensamento de crianças que freqüentam as séries iniciais da escola de ensino fundamental, realizamos uma pesquisa em Campinas - SP. Para saber com que idade as crianças de Campinas eram capazes de raciocinar de acordo com a lógica de classes e relações, foi constituída uma amostra, pelo processo de estratificação proporcional segundo o tipo de escola que as crianças de 7 a 9 anos de idade frequientavam. Todos os nomes de crianças desta faixa etária foram relacionados em listas e procedeu-se à escolha aleatória de 324 sujeitos.

A referida amostra pode ser observada na tabela seguinte: 


\section{TABELA 1}

Amostra A - crianças de 7 a 9 anos de idade

\begin{tabular}{c|c}
\hline Tipo de Escola & N. o de Sujeitos \\
\hline Estadual & 238 \\
Municipal & 56 \\
Particular & 30 \\
\hline TOTAL & 324 \\
\hline
\end{tabular}

O raciocínio lógico dos sujeitos estudados foi determinado pelas provas piagetianas que permitem diagnosticar, por meio do método clínico, a natureza de suas estruturas de pensamento as quais se manifestam pela presença de noções de conservação, classificação e seriação em seus comportamentos ${ }^{1}$. Os resultados obtidos pelos componentes da amostra A encontram-se expressos na tabela 2.

TABELA 2

Resultados das provas piagetianas em crianças de $7-9$ anos de idade

\begin{tabular}{c|c|c|c|c}
\hline \multirow{2}{*}{ Idade } & \multicolumn{2}{|c|}{ Estágio de Desenvolvimento Intelectual } & \multirow{2}{*}{ TOTAL } \\
\cline { 2 - 4 } & Pré- Operatório & Transição & Op. Concreto & \\
\hline $7,0 \mid-7,5$ & 15 & 4 & 2 & 21 \\
$7,5 \mid-8,0$ & 46 & 15 & 4 & 61 \\
$8,0 \mid-8,5$ & 85 & 30 & 0 & 119 \\
$8,5-9,0$ & 63 & 54 & 6 & 123 \\
\hline TOTAL & 209 & 103 & 12 & 324 \\
\hline
\end{tabular}

\footnotetext{
${ }^{1}$ A noção de conservação implica na compreensão de que o todo se conserva independentemente do arranjo das partes, ou seja, que uma determinada quantidade de líquido não se modifica quando apenas for transvasada para outro recipiente ou que uma certa quantidade de massa se mantém a mesma quando se a submete a transformações. A noção de classificação operatória supõe o raciocínio lógico de inclusão de classes que se manifesta pela compreensão de que duas subclasses estão incluídas numa outra de maior extensão, por exemplo, $A+A^{\prime}=B$, sendo $A$ a subclasse das mulheres, $A^{\prime}$ a subclasse dos homens e $B$ a classe das pessoas. A noção de seriação implica que se agrupem os objetos de acordo com suas diferenças ordenadas. Em outras palavras, consiste em ordenar sistematicamente um conjunto de elementos que se diferenciam, em uma propriedade segundo a relação $A>B>C>D>E>F$ ou $A<B<C<D<E<F$ e admitir que um dos elementos medianos, por exemplo $C$, seja compreendido como ao mesmo tempo maior que $D$ e menor que $B$, se a relação for descendente e maior que $B$ e menor que $D$, no caso da ser ascendente.
} 
Como podemos constatar, 12 sujeitos, ou seja, $3,7 \%$ demonstraram possuir as estruturas lógicas elementares que correspondem ao estágio de desenvolvimento intelectual denominado operatório concreto ${ }^{2}, 103$ ou $31,8 \%$ manifestaram raciocínio de transição entre o pré-operatório e o operatório concreto ${ }^{3}$, e 209 ou $64 \%$ tiveram um desempenho tipicamente pré-operatório que se caracteriza pelo fato do raciocínio da criança ser pré-lógico e pela ausência das noções de conservação, classificação e seriação em seus comportamentos. Isso significa que apenas $3,7 \%$ dos sujeitos da amostra tinham possibilidade de raciocinar logicamente, pois demonstraram estar de posse das estruturas lógicas elementares que caracterizam o estágio de desenvolvimento operatório concreto. De acordo com a teoria piagetiana, somente 12 sujeitos que se encontravam nesse estágio, poderiam compreender os conteúdos que lhes ensinava a escola. A compreensão desses mesmos conteúdos era inacessível a 209 crianças cujo raciocínio era ainda pré-operatório. Aos 103 sujeitos que estavam no estágio de transição entre o estágio pré-operatório e o operatório concreto, a compreensão talvez fosse possível apenas parcialmente. Resultados semelhantes aos nossos foram encontrados por Castellano Campos (1989) na pesquisa intitulada Estágios do Desenvolvimento Cognitivo e suas Relações com os Determinantes SócioEconômicos, realizada em São Carlos -

${ }^{2}$ O estágio operatório concreto é aquele em que os processos mentais da criança tomam-se lógicos e ela demonstra possuir as noções de conservação das quantidades contínuas e descontínuas bem como as noções de classificação e seriação operatórias.

${ }^{3} \mathrm{O}$ estágio de transição é aquele em que a criança demonstra possuir algumas estruturas de pensamento operatório e outras não, ou seja, em algumas situações ela raciocina com lógica, outras não.
SP. Essa pesquisadora estudou 380 sujeitos de 5 a 13 anos de idade dos quais 80 não freqüentavam a escola, 140 freqüentavam escolas públicas e 160 escolas particulares. Os dados obtidos indicam que nenhum dos sujeitos não escolarizados se encontrava no estágio operatório concreto, enquanto que apenas $3,57 \%$ dos que pertenciam à escola pública estavam e 5\% dos que estudavam em escolas particulares haviam atingido o mesmo estágio.

Os dados de nossa pesquisa e os da pesquisa de Castellano Campos (1989) comprovam a existência de um atraso no desenvolvimento intelectual das crianças estudadas, tendo em vista os resultados de pesquisas realizadas por PIAGET e seus colaboradores que indicam ser o raciocínio operatório concreto típico de crianças de 7 a 8 anos de idade.

Variações na cronologia do processo de desenvolvimento foram constatadas em muitos estudos interculturais. PIAGET (1969) admite que tais variações podem ser explicadas pelas transmissões educativas e tradições culturais que se diferenciam de uma cultura para outra.

Para comprovar se seria possível evitar atrasos no desenvolvimento intelectual, realizamos uma pesquisa com crianças de 5 e 6 anos de idade, pertencentes a famílias de diferentes níveis sócioeconômicos e que estavam matriculadas em uma escola particular e quatro escolas municipais. Foram realizadas nove classes experimentais, sendo que três funcionaram em 1974 e seis, no ano seguinte. Constituíram o grupo experimental e de controle, respectivamente, 183 e 188 sujeitos. No início de cada ano escolar, foi aplicado o pré-teste aos componentes do grupo experimental, visando determinar os estágios de desenvolvimento dos sujeitos, para que se tivesse certeza de que esse 
grupo fosse formado somente por crianças tipicamente pré-operatórias. Os sujeitos desse grupo tiveram a oportunidade de participar de classes de educação pré-escolar que lhes propiciou um ambiente moral $e$ intelectualmente enriquecedor, capaz de compensar, por sua atmosfera e sobretudo pela abundância e diversidade do material usado, a pobreza do ambiente familiar no tocante aos estímulos, à curiosidade e à atividade (PIAGET, 1973,p.10). Naquela época, os procedimentos pedagógicos empregados nas classes do grupo experimental foram denominados de Processo de Solicitação do Meio. Tal processo consiste em oferecer à criança a oportunidade de se defrontar com situações-problema que geram conflitos e contradições que desencadeiam o processo de equilibração responsável pela construção das estruturas da inteligência. Desde 1980, o Processo de Solicitação do Meio passou a ser denominado PROEPRE (Programa de Educação PréEscolar). Nas classes dos sujeitos do grupo controle foi empregado o programa da escola que freqüentavam.

$\mathrm{Na}$ tabela 3 estão registrados os resultados obtidos pelos sujeitos do grupo experimental nas provas piagetianas para determinação do estágio de desenvolvimento intelectual.

\section{TABELA 3}

Resultados do pós-teste do grupo experimental distribuição por nível sócio-econômico

\begin{tabular}{c|c|c|c|c}
\hline \multirow{2}{*}{ N.S.E. } & \multicolumn{3}{|c|}{ Estágio de Desenvolvimento Intelectual } & \multirow{2}{*}{ TOTAL } \\
\cline { 2 - 4 } & Pré-Operatório & Transição & Op. Concreto & \\
\hline 1 & 4 & 3 & 21 & 28 \\
2 & 8 & 12 & 65 & 85 \\
3 & 1 & 1 & 25 & 27 \\
4 & 2 & 4 & 37 & 43 \\
\hline TOTAL & 15 & 20 & 148 & 183 \\
\hline
\end{tabular}

Os resultados do pós-teste do grupo experimental mostram que $80,87 \%$ atingiram o estágio operatório concreto, $10,29 \%$ passaram para o estágio de transição entre o pré-operatório e o operatório concreto e $8,2 \%$ permaneceram pré-operatórios. 


\section{TABELA 4}

Resultados do pós-teste do grupo controle

distribuição por nível sócio-econômico

\begin{tabular}{c|c|c|c|c}
\hline \multirow{2}{*}{ N.S.E. } & \multicolumn{2}{|c|}{ Estágio de Desenvolvimento Intelectual } & \multirow{2}{*}{ TOTAL } \\
\cline { 2 - 4 } & Op. Concreto & Transição & Op. Formal & \\
\hline 1 & 56 & 1 & 0 & 57 \\
2 & 57 & 5 & 0 & 62 \\
3 & 26 & 0 & 0 & 26 \\
4 & 41 & 2 & 0 & 43 \\
\hline TOTAL & 180 & 8 & 0 & 188 \\
\hline
\end{tabular}

Os dados registrados na tabela 4 demonstraram que $95,75 \%$ dos sujeitos permaneceram no estágio pré-operatório, $4,25 \%$ encontravam-se em transição. Nenhum sujeito desse grupo apresentou desempenho correspondente ao estágio operatório concreto.

Comparando-se os resultados de ambos os grupos conclui-se que o Processo de Solicitação do Meio contribuiu para que as crianças pertencentes ao grupo experimental apresentassem um progresso bastante significativo. De fato, enquanto que $80,87 \%$ dos sujeitos que constituíam o grupo experimental apresentaram o progresso máximo, o mesmo não aconteceu com nenhuma criança do grupo controle.

Há ainda um outro aspecto a ser ressaltado. Quando os resultados do grupo experimental foram submetidos ao teste estatístico, verificou-se que a proporção de sujeitos que atingiram o estágio das operações concretas, não aumentou em relação direta ao nível sócio-econômico como era esperado. Isso significa que o nível sócio-econômico não exerceu influência no progresso no desenvolvimento intelectual apresentado pelas crianças desse grupo. As principais conclusões a que se chegou, a partir da análise dos resultados obtidos nesse trabalho, foram as seguintes:

O Processo de Solicitação do Meio foi eficaz para promover o progresso no desenvolvimento cognitivo dos alunos que pertenciam ao grupo experimental. Ao contrário, os programas empregados nas classes constituídas pelos integrantes do grupo controle não contribuíram para que os mesmos progredissem. Isso porque nenhum aluno desse grupo apresentou desempenho correspondente ao estágio das operações concretas.

O nível sócio-econômico ao qual os sujeitos pertenciam não teve influência no progresso cognitivo. Isso pode ser explicado pelos seguintes fatores:

- nas classes experimentais o ambiente sócio afetivo era livre de tensões, coação, pressão;

- relacionamento professor/aluno baseavase a aceitação, no respeito mútuo;

- estágio de pensamento em que as crianças se encontravam, suas 
necessidades e interesses constituíam um quadro referencial a partir do qual o professor planejava e organizava situações em que a criança, ao perceber a existência de um problema e tentava resolvê-lo. Isso porque, diante de uma situação-problema, a criança põe em funcionamento seus esquemas de assimilação que poderão dar origem a novos esquemas necessários para chegar à solução do problema que despertou nela a curiosidade ou, melhor dizendo, a necessidade de conhecer que é inerente às estruturas da inteligência, independentemente do nível sócioeconômico ao qual ela pertença.

De acordo com PIAGET, as estruturas da inteligência não são inatas e somente se impõe como necessárias depois de um longo processo de construção. Esse processo é desencadeado espontaneamente a partir das trocas que se estabelecem entre o sujeito e o meio. O progresso será rápido ou lento, dependendo das possibilidades do sujeito e das solicitações do meio. Por conseguinte, tratando-se de sujeitos que não apresentam patologias e nem déficits mentais que dificultam o processo de aprendizagem, pode-se afirmar que o atraso na progressão dos estágios de desenvolvimento contatado pode ser evitado, tal como os resultados dessa pesquisa confirmaram.

O Processo de Solicitação do Meio (PROEPRE) pode ser considerado um dos meios para evitar o aparecimento tardio das estruturas da inteligência operatória concreta. O fato de $80,87 \%$ dos integrantes do grupo experimental terem conseguido construir tais estruturas, em apenas um ano escolar, pode ser atribuído à eficácia do referido processo. Com efeito, se as crianças de 5-6 anos de idade, tipicamente operatórias, progrediram a ponto de atingir o estágio das operações concretas aos 6 e 7 anos, respectivamente, é porque a solicitação do meio foi adequada para desencadear, na maior parte dos sujeitos, o processo de equilibração a partir do qual são construídas as estruturas que possibilitam a conquista do conhecimento. Nossa pesquisa comprovou a viabilidade de um programa pedagógico que favorece o desenvolvimento da criança pré-escolar, o qual passamos a denominar PROEPRE (Programa de Educação Pré-Escolar) desde 1980. Os resultados dessas pesquisas suscitaram novas questões que determinaram a realização de outros estudos.

As crianças do grupo experimental que chegaram a construir as estruturas lógicas elementares, ao ingressar na escola de primeiro grau teriam, de acordo com as afirmações de PIAGET (1979, p.55), os instrumentos psicológicos necessários à compreensão dos conteúdos escolares pertinentes a esse grau de ensino. Ressalta-se, mais uma vez, que as crianças do grupo controle não apresentaram progresso no que diz respeito à construção das estruturas da inteligência operatória. Esse fato nos permite afirmar que a educação recebida na pré-escola que freqüentaram não desempenhou uma de suas funções mais importantes que é a de contribuir para que as crianças construam instrumentos intelectuais que lhes permitam logicizar a realidade. Por outro lado, a escola de ensino fundamental de Campinas não estava propiciando aos alunos de 7 a 9 anos de idade um ambiente educacional adequado que lhes possibilitasse construir as operações concretas, condição para a compreensão dos conhecimentos que a escola se propõe a transmitir.

Se considerarmos os princípios da psicologia genética, segundo os quais há 
entre o desenvolvimento afetivo, cognitivo e social um estreito paralelismo de modo que as mudanças que ocorrem em cada um desses aspectos refletem mudanças nos outros também, pode se afirmar que os dados de nossa pesquisa indicam que tanto a pré-escola como as escolas de ensino fundamental não estavam contribuindo para o desenvolvimento psicossocial de seus alunos.

$\mathrm{Na}$ medida que nossa primeira pesquisa prosseguia, a Secretaria Municipal de Educação de Campinas-SP, interessou-se por implantar o Processo de Solicitação do Meio em algumas classes de educação pré-escolar. Por esse motivo, em 1975, professores da pré-escola da rede municipal participaram de um curso de aperfeiçoamento, sob nossa responsabilidade, na Universidade Estadual de Campinas e, a partir de 1976, o referido processo passou a ser empregado em aproximadamente 15 classes. Os resultados obtidos na fase de implantação do Processo de Solicitação do Meio nesse sistema de ensino confirmaram os resultados da pesquisa inicial.

Tínhamos, naquela ocasião, mais dados que comprovaram a possibilidade de evitar que houvesse atraso no processo de desenvolvimento de crianças préoperatórias que frequientavam a préescola. Entretanto, algumas questões justificavam, a nosso ver, o prosseguimento desse estudo iniciado em 1974. Assim, por exemplo, julgávamos muito importante saber como os sujeitos que atingiram os estágios de transição e operatório concreto estavam se saindo na escola de ensino fundamental. Estavam eles mais avançados na construção das estruturas da inteligência do que aqueles que não participaram do Processo de Solicitação do Meio na pré-escola? Em outras palavras, os efeitos do processo de Processo de Solicitação do Meio ou PROEPRE se prolongariam pelos anos subseqüentes? Enfim, a construção das estruturas operatórias antes do ingresso na escola de ensino fundamental facilitaria a compreensão dos conteúdos curriculares?

Com o objetivo de responder a essas questões, realizamos a pesquisa Solicitação do Meio e Desenvolvimento Intelectual no período de 1980 a 1982 . Os sujeitos dessa pesquisa foram distribuídos em dois grupos: experimental e controle. O grupo experimental era constituído por sujeitos pertencentes ao grupo experimental da pesquisa Estudo Sobre a Relação entre a Solicitação do Meio e a Formação da Estrutura Lógica no Comportamento da Criança e às classes experimentais da rede pré-escolar municipal na qual o Processo de Solicitação do Meio foi utilizado. A população era formada de 990 sujeitos dos quais 133 foram encontrados no período de tempo de que dispúnhamos para realizar a coleta de dados. Não houve sorteio aleatório, pois se esperava estudar o maior número possível de sujeitos. A amostra extraída representava $13 \%$ da população.

O grupo controle foi constituído de 111 sujeitos, dentre os quais havia aqueles que tinham pertencido ao grupo controle da citada pesquisa e outros sorteados aleatoriamente dentre aqueles que tinham as mesmas idades e estavam freqüentando as mesmas séries que os sujeitos do grupo experimental.

Os sujeitos de ambos os grupos pertenciam a três níveis sócioeconômicos: alto (4), médio (3), baixo (2), e freqüentavam, na época da realização do trabalho, da $4^{\mathrm{a}}$ a $8^{\mathrm{a}}$ série do ensino fundamental. Não encontramos nenhum sujeito de nível sócio-econômico 
muito baixo freqüentando a escola de ensino fundamental.

A avaliação do desenvolvimento intelectual dos sujeitos desse estudo foi realizada individualmente de acordo com os procedimentos habituais método clínico utilizado por PIAGET e seus seguidores. Para determinação do estágio de desenvolvimento intelectual foram utilizadas as seguintes provas da conservação do volume que é adquirida mais tardiamente, depois das conservações das quantidades numéricas do líquido, da massa e do peso; das combinações de fichas coloridas que permitem determinar se o sujeito possui o raciocínio combinatório e das oscilações do pêndulo que indicam a capacidade de pensar, valendo-se do raciocínio hipotético-dedutivo ${ }^{4}$. Por meio das provas mencionadas é possível verificar se o sujeito encontra-se ou não no estágio de desenvolvimento operatório formal.

Somente serão apresentadas, neste trabalho, os resultados referentes às variáveis Solicitação do Meio e Desenvolvimento Intelectual relativas ao nível sócio-econômico. Da tabela 5 constam os resultados do grupo experimental que era constituído, como já foi dito, por crianças que participaram do PROEPRE quando estavam na préescola.

\footnotetext{
4 Trata-se de um tipo de raciocínio que consiste em formular hipóteses e deduzir a hipótese verdadeira a partir da experimentação. É o raciocínio do cientista que possibilita ao sujeito chegar a compreender o real a partir do possível.
}

\section{TABELA 5}

Resultados gerais do grupo experimental distribuição por nível sócio-econômico

\begin{tabular}{r|rr|c}
\hline \multicolumn{3}{c|}{ Estágio de Desenvolvimento Intelectual } & TOTAL \\
\hline $\begin{array}{l}\text { Op. } \\
\text { Concreto }\end{array}$ & Transição & Op. Formal & \\
\hline 0 & 8 & 24 & 32 \\
4 & 15 & 52 & 71 \\
0 & 1 & 29 & 30 \\
\hline $\mathbf{4}$ & $\mathbf{2 4}$ & $\mathbf{1 0 5}$ & $\mathbf{1 3 3}$ \\
\hline
\end{tabular}

$\mathrm{Na}$ tabela seguinte estão registrados os resultados nas provas aplicadas ao grupo controle que era formado de crianças que quando freqüientaram a pré-escola não participaram do PROEPRE.

\section{TABELA 6}

Resultados gerais do grupo controle distribuição por nível sócio-econômico

\begin{tabular}{r|r|r|r}
\hline \multicolumn{3}{c|}{ Estágio de Desenvolvimento } & \multirow{2}{*}{ Intelectual } \\
\cline { 1 - 2 } $\begin{array}{r}\text { Op. } \\
\text { Concreto }\end{array}$ & \multicolumn{1}{|c}{ Transição } & Op. Formal & \\
\hline 7 & 11 & 12 & 30 \\
\hline 21 & 22 & 14 & 57 \\
\hline 2 & 8 & 14 & 24 \\
\hline $\mathbf{3 0}$ & $\mathbf{4 1}$ & $\mathbf{4 0}$ & $\mathbf{1 1 1}$ \\
\hline
\end{tabular}

Os resultados dessa pesquisa demonstram que os efeitos do Processo de Solicitação do Meio ou PROEPRE se mantêm mesmo depois de decorridos 4 a 8 anos

A superioridade do grupo experimental em relação ao grupo controle pode ser constatada quando se comparam as tabelas 5 e 6 , nas quais os resultados estão registrados.

A explicação para o fato de os sujeitos do grupo experimental estarem ainda mais 
adiantados que os do grupo controle, mesmo depois de cessada a estimulação que recebiam na pré-escola pode ser encontrada dentro na teoria de PIAGET. Se as crianças do grupo experimental atingiram o estágio operatório concreto aos 6-7 anos, portanto, muito mais cedo do que as crianças do grupo controle, por seguinte, o mais provável é que também chegassem mais cedo ao estágio do pensamento operatório formal.

Nesse estudo, o desempenho escolar dos sujeitos do grupo experimental foi analisado apenas quanto à repetência. Decidimos não fazer um levantamento de notas de provas e exames porque, em geral, as avaliações realizadas pela escola se limitam a constatar os erros e os acertos nas produções dos alunos. Somam-se os pontos dos acertos, diminuem-se os relativos aos erros e obtém-se uma nota a ser atribuída ao aprendiz. Como as provas, exercícios, deveres, perguntas escritas ou orais não constituem indicadores que permitam ao professor perceber se o conteúdo foi compreendido ou não, torna-se desnecessário saber que notas os sujeitos dessa pesquisa obtiveram nos anos em que frequientaram a escola de ensino fundamental.

$\mathrm{O}$ que nos interessava saber quanto ao desempenho escolar dos sujeitos dessa pesquisa, era se os instrumentos psicológicos que haviam construído no final da pré-escola possibilitaram-lhes a compreensão do que foi ensinado na escola. Infelizmente, essa compreensão é entendida apenas a partir de respostas certas que podem expressar tão somente informações retidas na memória.

É importante ressaltar que dos 133 sujeitos do grupo experimental, somente 10 haviam, repetido uma única vez uma das séries do primeiro grau. Os motivos invocados para justificar a repetência foram os mais variados, tais como: períodos longos de enfermidade; transferência de uma escola para outra devida ao fato de a família ter passado a residir em outro bairro; impossibilidade de continuar os estudos durante um período de tempo para cuidar de irmãos menores, enquanto a mãe trabalhava fora; necessidade de interromper os estudos porque a família mudou-se para outra cidade onde não havia vaga nas escolas públicas no meio do ano escolar. É interessante notar que nenhuma repetência foi explicada pela impossibilidade de aprender. Um único sujeito disse que havia repetido a $3^{\mathrm{a}}$ série porque não gostava da professora.

A pesquisa relatada comprovou empiricamente a eficácia de um programa educacional destinado o desenvolvimento infantil. Neste momento, parece-nos oportuno tratar de descrever em linhas gerais prática pedagógica por meio da qual esse programa se concretiza.

O construtivismo é uma teoria epistemológica para a qual o conhecimento é fruto de uma construção pessoal, resultado de um processo interno de pensamento em que o sujeito coordena diferentes noções entre si, atribuindo-lhes um significado, organizando-as e relacionando-as àquelas já possuía anteriormente. Essa construção do conhecimento é um processo inalienável e intransferível decorrente das trocas que se estabelecem entre o sujeito e o meio físico e/ou social que mobiliza o funcionamento intelectual do indivíduo possibilitando-lhe adaptar-se às situações novas, facilitando o acesso a novas aprendizagens, à compreensão de novas situações e à invenção de soluções a problemas que se possam apresentar na vida, graças a sua capacidade de compreender e generalizar. 
Desde que a teoria construtivista explica que o conhecimento é construído pela criança, o papel do(a) professor(a) consiste em criar condições favoráveis a essa construção. Ao invés de transmitir o conhecimento, sob a forma de soluções prontas, tentando inculcar o seu conhecimento de adulto na cabeça dos alunos, é preciso encorajar a criança a encontrar por si as melhores formas de resolver os problemas que desafiam sua curiosidade e estimulam a sua reflexão. Isso não significa que as crianças devem ser totalmente livres, dirigindo suas ações como bem lhes aprouver, mas sim que a intervenção do(a) professor(a) é necessária e salutar, pois a interação social com o adulto é indispensável para o desenvolvimento do pensamento. A intervenção do(a) professor(a) é absolutamente necessária tendo em vista que suas incitações podem fazer a criança refletir sobre suas próprias ações e conseguir explicar os fatos que observa e, por conseguinte , caminhar em direção da estruturação do conhecimento.

As situações que estimulam o desenvolvimento são aquelas em que as crianças têm a oportunidade de descobrir conceitos e noções a partir da exploração ativa dos objetos de que dispõe no ambiente escolar. Pode-se afirmar que criar tais situações e encorajar a criança a buscar respostas para suas próprias questões exige uma grande habilidade, por parte do(a) professor(a) . De um lado, ele não pode assumir a direção das atividades infantis, de outro, não pode ficar alheio a essas atividades. E preciso interrogar a criança no momento oportuno para poder seguir os caminhos de seu pensamento e possibilitar-lhes ir além. Para isso é importante que o(a) professor(a) trabalhe ao lado das crianças, num clima de cooperação e respeito mútuo, incentivando-as a fazer perguntas e procurar respostas, organizando situações que possam gerar conflitos cognitivos ou sócio-cognitivos que por sua vez desencadeiam o processo de equilibração responsável pela construção do conhecimento.

A nosso ver, o(a) professor(a) precisa conhecer bem os fundamentos psicológicos que orientam sua prática a fim de que sejam evitadas incoerências, tão frequientemente observadas, entre princípios teóricos e prática educativa. Com efeito, não é possível pretender, por exemplo, estimular a aquisição de estruturas de seriação pela criança oferecendo-lhe um conjunto de folhas de árvores (recortadas em cartolina, que se diferenciam pelo tamanho e intensidade de cor), dizendo-lhe que ela deve observar que existe uma folha que é a menor e a mais clara e que também existe uma folha que é a maior e a mais escura. Ora, a criança por si, ao manipular e observar esse material, deve chegar a perceber que a folha menor é também a mais clara e que a maior é, por sua vez, a mais escura. Do mesmo modo, não se pode sugerir à criança que arrume essas folhas em fila desde as mais claras e menores até as mais escuras e maiores, pois a maneira pela qual a criança arruma esse conjunto de objetos reflete uma estrutura cognitiva subjacente ao seu comportamento. Se é o(a) professor(a) quem determina os critérios da ordem em as folhas devem ser colocadas, certamente o comportamento da criança não irá refletir a estrutura de seu pensamento, mas sim, a estrutura do pensamento do(a) professor(a). É manipulando um conjunto de objetos como esse que a criança poderá chegar a criar a multiplicação biunívoca de relações que consiste em ordenar os objetos de acordo com suas diferenças considerando-se dois atributos, nesse 
caso, o tamanho e a cor. A intervenção do(a) professor(a), numa situação como essa, deverá ser no sentido de solicitar à criança que explicite qual o critério usado por ela ao fazer uma seriação e não no sentido de determinar o que deve ser feito.

É preciso evitar a submissão intelectual que ocorre quando o(a) professor(a) tenta "passar" para a cabeça do aluno o seu conhecimento de adulto, roubando a oportunidade deste aluno construir o conhecimento por si próprio. Isso implica que o(a) professor(a) esteja constantemente atento ao desenvolvimento de seus alunos e ao que eles fazem, aproveitando as oportunidades que surgem para fazê-los reconstituírem e tomarem consciência de suas ações e passarem do plano do "fazer" para o "compreender". Embora confira um relevo especial à atividade espontânea da criança, essa prática docente não anula $o$ papel $\operatorname{do}(\mathrm{a})$ professor(a) . Ao contrário,

\section{(...)o educador continua} indispensável, a título de animador, para criar as situações e armar os dispositivos iniciais capazes de suscitar problemas úteis à criança, $e$ para organizar, em seguida, contraexemplos que levem à reflexão $e$ obriguem ao controle das soluções demasiado apressadas ...(PIAGET, 1973, p. 18).

Para que isso ocorra, o educador deverá deixar de ser aquele que ensina (transmite o conhecimento), para se transformar naquele que cria as situações mais estimuladoras para que a criança, por si mesma, descubra ou reinvente conhecimento. Na sua interação com a criança o(a) professor(a) precisa ter cuidado para não induzir suas respostas.
Convém ressaltar também que as respostas "erradas" não devem ser corrigidas. $\mathrm{O}(\mathrm{a})$ professor(a) poderá fornecer novos elementos a partir dos quais a criança poderá ou não reformular seu pensamento. Da mesma forma, quando a criança dá respostas certas é necessário colocar contra-argumentos que permitam verificar até que ponto ela está convicta ou não.

Convém insistir que os procedimentos docentes para cada atividade devem servir de idéias, diretrizes e de maneira alguma podem ser usados como receitas. Não há "receitas pedagógicas" para uma prática docente como essa. $\mathrm{O}(\mathrm{a})$ professor(a) que a utiliza deve encontrar um meio de colocar à disposição de seus alunos uma grande variedade de material, de encorajá-los a serem ativos e curiosos, de responder às suas necessidades afetivas e de favorecer a interação social entre eles, criando, desse modo, condições favoráveis para que cada um se desenvolva na medida de suas possibilidades.

É importante ressaltar também que os princípios psicológicos da teoria piagetiana não podem ser transpostos para a prática docente sem que sejam objeto de verificação e comprovação experimental, pois somente os resultados da experiência empírica poderão apontar se, de fato, a aplicação desses princípios tem um valor real.

\section{CONSIDERAÇÕES FINAIS}

Resumindo o que foi exposto podemos notar que a prática pedagógica do(a) professor(a) direciona as atividades curriculares de maneira a assegurar " $a$ ação sobre os objetos" e a "interação social" que, segundo PIAGET, são 
indispensáveis para a favorecer construção da lógica e da moralidade. Concebemos, dessa forma, uma prática docente que propicia atividades reais (experimentais) desenvolvidas em cooperação, pois a inteligência lógica se elabora em função da ação e das trocas sociais.

Os estudos de PIAGET sobre o desenvolvimento do pensamento infantil levaram-no a concluir que a lógica e a moralidade não são inatas na criança. Para ele, esse fato altera os termos clássicos da pedagogia e, por conseguinte, o significado do direito à educação. Sobre isso PIAGET argumenta que a proposição "Toda pessoa tem direito à educação" contida no artigo 26 da Declaração Universal dos Direitos do Homem deve ser entendida como não somente o direito de freqüentar uma escola mas sim o direto de receber nessa escola uma educação que garanta o pleno desenvolvimento de sua personalidade.

A prática docente quando fundamentada nos conhecimentos de psicologia, da filosofia e sociologia da educação, pode ser um meio eficaz de propiciar as condições necessárias para que o desenvolvimento da criança se realize em ritmo normal, evitando, portanto, que haja atrasos. À educação cabe a responsabilidade muito maior do que a de assegurar a toda criança a aprendizagem da língua escrita e da matemática, visto que é preciso garantir que a escola ofereça a toda criança as possibilidades de um completo desenvolvimento intelectual, afetivo e sócio-moral.

A educação escolar que tem como objetivo o desenvolvimento psicológico da criança não pode mais ser privilégio de um pequeno número de crianças. A educação escolar deve propiciar à criança contatos e trocas sociais que são indispensáveis para sua socialização e um ambiente educativo que estimule o desenvolvimento de sua inteligência, iniciativa, autonomia e criatividade.

Torna-se, portanto, imprescindível que os responsáveis pela educação de cada país tomem cada vez mais consciência do valor da educação escolar e das verdadeiras dimensões de seus efeitos e, consequentemente, envidem os esforços necessários para que um número cada vez maior de crianças recebam os estímulos que precisam nesta fase crucial do seu desenvolvimento.

$\mathrm{O}$ direito à educação escolar deve ser assegurado a toda criança. Este é, segundo PIAGET, nem mais nem menos, o direito que tem o indivíduo de se desenvolver normalmente em função das possibilidades de que dispõe, e a obrigação, para a sociedade, de transformar essas possibilidades em realizações efetivas e úteis (I973, p. 55). 


\section{REFERÊNCIAS BIBLIOGRÁFICAS}

CASTELLANO CAMPOS, Elizabete Gabriela. Estágios do desenvolvimento cognitivo $e$ as relações com os determinantes sócio-econômicos. Campinas, SP, 1989. Tese (Doutorado) - Faculdade de Educação, UNICAMP.

KAMII, Constance e DEVRIES, Rheta. PIAGET PARA A EDUCAÇÃO PRÉ-ESCOLAR. Porto Alegre: Artes Médicas SUL, 1991.

MANTOVANI DE ASSIS, Orly Zucatto. A Solicitação do Meio $e$ a Construção das Estruturas Lógicas Elementares na Criança. Campinas,1976, Tese de Doutorado, Faculdade de Educação - UNICAMP.

. Estudo Sobre a Relação Entre a Solicitação do Meio e a Formação da Estrutura Lógica no Comportamento da Criança. Relatório de Pesquisa. UNICAMP/INEP, 1977.

\section{UMA NOVA}

METODOLOGIA DE EDUCAÇÃO PRÉ-ESCOLAR. São Paulo: Pioneira. 1993.

\section{- Solicitação do Meio $e$ Desenvolvimento Intelectual. Relatório de Pesquisa, INEP, 1981.}

L'école et la construction des structures de l'intelligence chez I'enfant . in Bulletin de Psychologie
- Septembre / Octobre 1998 - Paris: France.

ASSIS, Orly Mantovani de, ASIS, Múcio Camargo de (Org.) PROEPRE Fundamentos Teóricos LPG/UNICAMP: Campinas, 1999.

(Org.) PROEPRE : Prática Pedagógica- LPG/UNICAMP: Campinas, 1999.

MORENO Montserrat y SASTRE, Genoveva. APRENDIZAJE Y DESARROLHO INTELECTUAL. Barcelona: Gedisa, 1987.

PIAGET, Jean. Apprentissage et connaissance. In: PIAGET, Jean, Gréco, Pierre. Études d'épistemologie génëtique. Paris : Presses Universitaires de France, 1959. p.21-67 v.7.

PSYCHOLOGIE ET PEDAGOGIE. Paris: Dunod, 1969.

A GENNESE DAS ESTRUTURAS LÓGICAS ELEMENTARES NA CRIANÇA. Trad.:Álvaro Cabral, Rio de Janeiro: Zahar Editores, 1971.

PARA ONDE VAI A EDUCAÇÃO? Trad.: Ivette Braga. Rio de Janeiro: José Olympio, 1973.

A Teoria de Jean Piaget, in CARMICHAEL. Manual de Psicologia da Criança. Organizado 
por Paul Mussen ,São Paulo: Editora da USP, 1977, vol. IV, p. 71 a 116.

\begin{tabular}{|c|c|c|}
\hline & LOS & \\
\hline POSTERGADOS & $-\mathrm{A}$ & \\
\hline $\begin{array}{l}\text { infância. Buenos } \\
\text { Unicef, } 1975 \text {. }\end{array}$ & Aires: & \\
\hline
\end{tabular}

Orly Zucatto Mantovani de Assis

Profa. Dra. da Faculdade de Educação

UNICAMP

Coordenadora do

Laboratório de Psicologia Genética da

Faculdade de Educação/UNICAMP

e-mail: orly@unicamp.br 